\title{
Assessment of inhibitory control in crack and/or cocaine users: a systematic review
}

\author{
Avaliação do controle inibitório em usuários de cocaína e/ou crack: uma \\ revisão sistemática
}

\author{
Fernanda Rasch Czermainski, Alice Rodrigues Willhelm, Álvaro Zaneti Santos, \\ Mayra Pacheco Pachado, Rosa Maria Martins de Almeida
}

\begin{abstract}
Objective: Impairments involving inhibitory control have been considered central deficits in drug users, but it appears that dysfunctions may be specific to users' drug of choice. This article aims to review recent findings on inhibitory control impairment in samples of crack and/or cocaine users.

Methods: Searches were conducted on the PubMed, PsycINFO, and Web of Knowledge databases in two stages according to eligibility criteria. Initially, databases were searched and the titles and abstracts of results were analyzed and then selected articles were read in full. Inclusion criteria were: empirical articles written in English, Portuguese, or Spanish, published in the last ten years and involving the assessment of inhibitory control in crack and/or cocaine users.

Results: The database searches returned a total of 3,796 titles, 56 of them were selected initially and then a further 20 were excluded. Thirty-six articles were included in this review. In $90 \%$ of the studies reviewed the presence of inhibitory control deficits was reported, verified by impaired cognitive processing and response monitoring, as well as high levels of impulsiveness, regardless of the pattern of crack and/or cocaine consumption (recreational or chronic). Former users showed high levels of impulsiveness even after long periods of abstinence.

Conclusions: Crack and/or cocaine users may have inhibitory control deficits, irrespective of different consumption patterns. High levels of impulsiveness can represent a factor of vulnerability to drug use and relapse.
\end{abstract}

Keywords: Drugs, assessment, inhibition, cognition.

\section{Resumo}

Objetivo: Prejuízos envolvendo o controle inibitório têm sido considerados déficits centrais em usuários de substâncias psicoativas, contudo parece haver disfunções específicas de acordo com a droga de escolha. Este artigo teve por objetivo revisar os achados recentes sobre alterações do controle inibitório em amostras de usuários de cocaína e/ou crack.

Método: A pesquisa foi realizada nas bases de dados PubMed, PsycINFO e Web of Knowledge, em duas etapas, de acordo com os critérios de elegibilidade: inicialmente foi feita uma pesquisa nas bases de dados com análise dos títulos e resumos; após, os artigos foram lidos na íntegra. Os critérios de inclusão foram: artigos empíricos publicados em inglês, português ou espanhol, nos últimos 10 anos e que tenham avaliado o controle inibitório em usuários de cocaína e/ou crack.

Resultados: Do total de 3.796 resultados, 56 títulos foram selecionados, sendo 20 excluídos. Como resultado, 36 artigos foram incluídos na revisão. Em $90 \%$ dos estudos revisados, foi relatada a presença de déficits de controle inibitório, verificados através de prejuízos no processamento cognitivo e no monitoramento de respostas, além de níveis elevados de impulsividade, independentemente do padrão de consumo de cocaína e/ou crack (uso recreativo ou crônico). Usuários em abstinência apresentaram níveis elevados de impulsividade, mesmo após longos períodos sem uso da droga.

Conclusão: Usuários de cocaína e/ou crack podem apresentar prejuízos de controle inibitório apesar dos diferentes padrões de consumo. Níveis elevados de impulsividade podem constituir fator de vulnerabilidade para o uso de drogas e para a recaída. Descritores: Drogas, avaliação, inibição, cognição.

* Universidade Federal do Rio Grande do Sul (UFRGS), Porto Alegre, RS, Brazil.

Financial support: Coordenação de Aperfeiçoamento de Pessoal de Nível Superior (CAPES).

Submitted Jul 05 2016, accepted for publication Feb 162017.

Suggested citation: Czermainski FR, Willhelm AR, Santos AZ, Pachado MP, de Almeida RM. Assessment of inhibitory control in crack and/or cocaine users: a systematic review. Trends Psychiatry Psychother. 2017;39(3):216-225. Epub 14 Aug 2017. http://dx.doi.org/10.1590/2237-6089-2016-0043 


\section{Introduction}

Recently, consumption of psychoactive substances (PS) has increased considerably, with new and powerful drugs emerging constantly. In Brazil, crack consumption is an important public health problem and crack is the illicit psychoactive substance that, together with cocaine, is responsible for greatest treatment demand. ${ }^{1,2}$ Crack is a stimulant substance derived from cocaine which, when smoked, produces powerful euphoria of short duration, followed by intense craving. ${ }^{3}$ The result of these properties is that compulsive consumption of crack until complete exhaustion is common. This causes users to be highly vulnerable to clinical diseases, impulsive behavior, violence, and promiscuity, in order to obtain the drug. ${ }^{4-6}$

The profile of crack users is generally young adults who are users of multiple PS, but adopt crack as their drug of choice. ${ }^{7-9}$ The most common pattern of crack consumption described in the literature is characterized by loss of control, seeking behavior (despite obvious harm to various aspects of life), intense craving, and frequent relapses. ${ }^{10}$ These characteristics are associated with changes to neural circuits that manage behavioral processes, such as reward and conditioning behaviors; and cognitive processes, such as executive functioning and inhibitory control. ${ }^{11-13}$

According to the three-factor model of Barratt's impulsiveness scale, ${ }^{14}$ it is a broad construct that can be divided into independent dimensions: motor impulsiveness, related to deficits in response inhibition; attentional impulsiveness, related to difficulty resisting distracting stimuli; and nonplanning impulsiveness, linked to an incapacity to engage in long term planning, prioritizing immediate gains. Studies with samples of cocaine and/or crack users have reported increased impulsive behavior, loss of emotional control, inconsistency in delayed gratification tasks, lack of interest in others' needs, and a preference for magical and irrational explanations to solve problems. ${ }^{15-20} \mathrm{High}$ levels of impulsiveness can be observed in cocaine and/ or crack users, when drug consumption is maintained despite the individual being able to perceive the harm caused by consumption. There is therefore a dissociation between wanting and liking, which is most salient among crack users. ${ }^{21}$

Inhibitory control is a subcomponent of impulsiveness that plays an important role in Substance-Related Disorders (SRD). ${ }^{22}$ It is related to the capacity to be flexible and to adapt behavior according to context. This capacity, together with adequate management of impulsiveness, is considered essential to self-control. Studies with cocaine and/or crack users have provided evidence of impairment of inhibitory control related both to input (attentional selection, visual scanning, dealing with irrelevant information biases) and to output (response inhibition) of the inhibitory system.

Abnormalities related to impulsiveness and inhibitory control may be caused by cocaine and/or crack abuse, but they may also be associated with a greater propensity to problematic drug use, meaning that it is relevant to study this subject. This article was written with the objective of reviewing studies that have evaluated inhibitory control in samples of cocaine and/or crack users over the last ten years. The objectives of the review were: 1 ) to review recent findings on inhibitory control deficits in samples of cocaine and/or crack users; 2) to determine which tests/tasks have been used to evaluate inhibitory control and 3 ) to assess convergence between the findings of the studies reviewed.

\section{Method}

A systematic review of studies published over the last ten years (2005 to 2015) was conducted during January of 2016. PubMed, PsycINFO and Web of Knowledge, databases were searched using the following terms: [inhibitory control AND neuropsychology]; [inhibitory control AND cocaine]; [inhibitory control AND crack]; [inhibition AND neuropsychology]; [inhibition AND cocaine]; and [inhibition AND crack]. The inclusion criteria for studies were as follows: 1) empirical articles that evaluated inhibitory control in cocaine and/or crack users; 2) articles published in English, Portuguese, or Spanish; and 3) full articles. The following types were excluded from the review: theoretical and review studies, studies with animal models, research testing medications/substances for treatment, and studies that did not explicitly assess inhibitory control in cocaine and/or crack users. Articles were initially selected on the basis of title and abstract and then assessed by three independent researchers, according to the inclusion and exclusion criteria of the review. After confirmation of criteria, selected studies were read in full.

\section{Results}

Initially, 3,796 results were returned by the searches using the terms selected. Of these, 652 were found on Pubmed, 190 on PsycINFO, and 2,954 on the Web of Knowledge. Search filters available on the databases (Figure 1) were applied with the objective of making a pre-selection of articles relevant to the 
review. After application of the search filters, articles were analyzed according to their titles and abstracts, resulting in selection of 56 studies, which were read in full. A further 19 articles were then excluded because they did not meet the inclusion criteria for the review (e.g.: studies that tested medication, did not assess inhibitory control, or did not study samples of cocaine and/or crack users) and one was excluded because it was a brief communication on a study that had already been included in the review. Additionally, two studies designed to investigate the acute effects of cocaine on performance in inhibition tasks were maintained because they report data relevant to the subject of the review. ${ }^{23,24}$

The primary objective in a large proportion of the studies analyzed was to investigate the neural correlates of inhibitory control. However, eight studies were excluded because they did not meet the inclusion criteria for the review: seven did not evaluate inhibition performance in their samples, only employing tests with the objective of assessing cerebral activation patterns during testing, and one study was designed to evaluate the influence of a medication on cognition in cocaine and/or crack users. After the inclusion and exclusion criteria had been verified, twelve studies of this subject were included in the review, accounting for $33 \%$ of all of the articles reviewed. At the end of this process, 36 articles were selected for inclusion in the review. Figure 1 can be consulted for additional information.
It contains a flow diagram illustrating the database searches and information on the results from each database, specified by combinations of search terms. Tables 1 and 2 list information on the studies that assessed inhibitory control and those that investigated inhibition and its neural correlates, respectively.

This review found that $90 \%$ of the studies (28) reported impaired inhibitory control in cocaine and/or crack users (CU), while $10 \%$ (3) did not. The remaining studies (5) were designed to investigate recovery of inhibitory control functions in abstinent cocaine and/ or crack users and their results cannot therefore be classified with relation to presence/absence of inhibition deficits. A small number of articles differentiated by route of cocaine administration (inhaled, smoked), but none of them included this information in the title or abstract. The term "crack" proved inadequate and insufficiently comprehensive for the database searches. In response, it was decided to use the term "cocaine and/or crack users", since the majority of study samples comprised users of multiple PS, which is consistent with the profile generally described in the literature..$^{7-9}$

With relation to the instruments employed to evaluate inhibitory control, the majority of these instruments use the response inhibition paradigm (Go/No-Go, Color-Word Stroop, and Stop-Signal). These tests demand dynamic inversion of a previoulsy learned pattern of successful reponses. They generally assess aspects related to the velocity of processing in execution of tasks, for example,

Initial search on databases

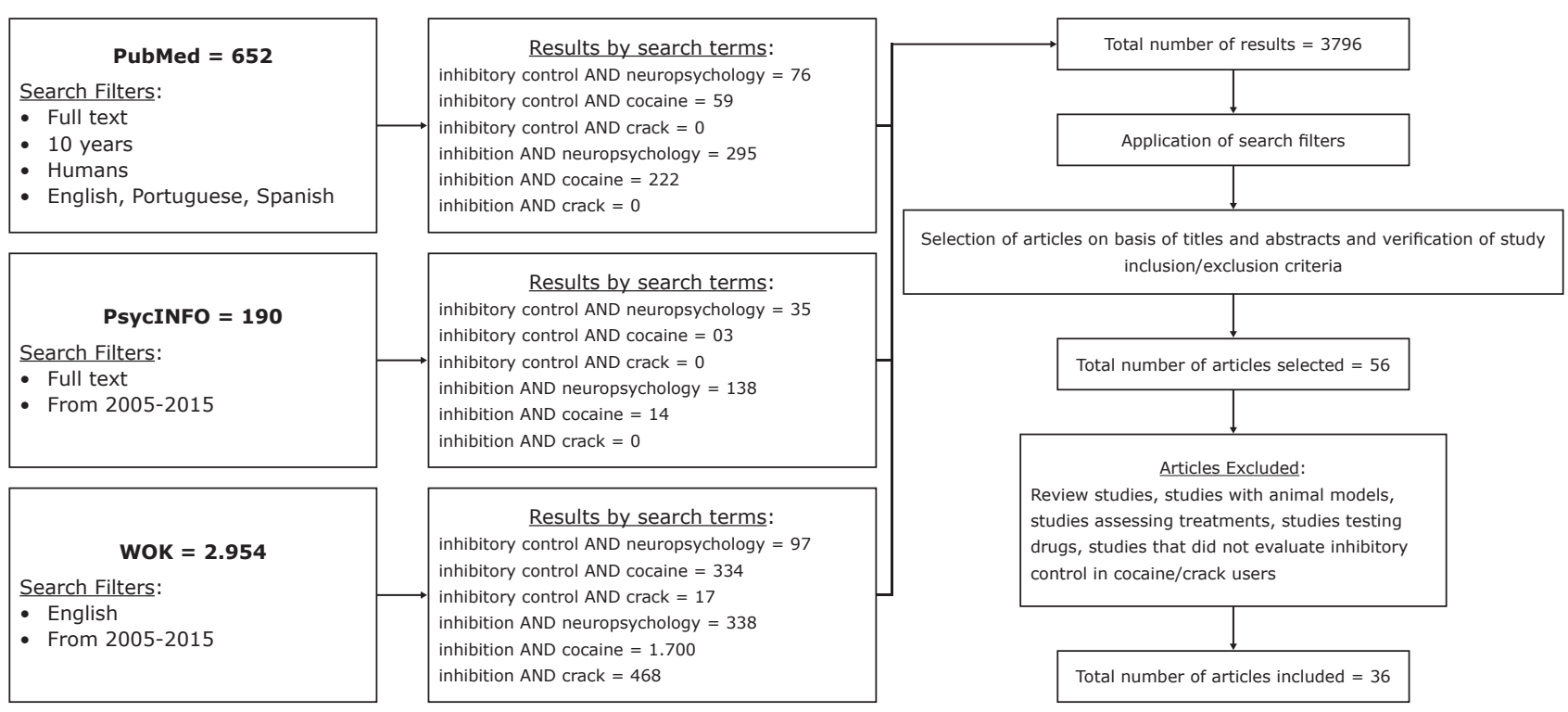

Figure 1 - Flow diagram of process for selection of studies for review 
Table 1 - Results of articles investigating inhibition deficits in cocaine/crack users

\begin{tabular}{|c|c|c|c|c|}
\hline Authors & Sample & Clinical and cognitive assessments & Inhibition assessment & $\begin{array}{l}\text { Impaired } \\
\text { inhibition? }\end{array}$ \\
\hline Albein-Urios et al. ${ }^{25}$ & $\begin{array}{l}\mathrm{CG}=20 \\
\mathrm{GCO}=29 \\
\mathrm{PG}=23\end{array}$ & Delay-Discounting; N-back; UPPS-P & CWIT & Yes (GDC and PG) \\
\hline Albein-Urios et al. ${ }^{26}$ & $\begin{array}{l}\mathrm{CG}=34 \\
\mathrm{GCO}=36 \\
\mathrm{GCDCB}=22 \\
\mathrm{GCDCC}=15\end{array}$ & $\begin{array}{l}\text { Category Test; D2; LNS (WAIS-III); } \\
\text { N-back; PBQ }\end{array}$ & CWIT & $\begin{array}{l}\text { Yes (GCDCB, GCDCC } \\
\text { and GDC) }\end{array}$ \\
\hline Colzato \& Hommel ${ }^{17}$ & $\begin{array}{l}\text { CG }=16 \\
\text { GURC }=13\end{array}$ & MINI; MPR & IOR & Yes (GURC) \\
\hline Colzato et al. ${ }^{27}$ & $\begin{array}{l}C G=13 \\
\text { GURC }=13\end{array}$ & MINI; MPR & Stop-signal & Yes (GURC) \\
\hline Fillmore \& Rush 28 & $\begin{array}{l}\mathrm{CG}=20 \\
\mathrm{GP}=20\end{array}$ & BDI; BPRS; DAST; K-BIT & Cue-dependent Go/No-Go & Yes (GP) \\
\hline Fillmore et al. ${ }^{23}$ & $\mathrm{GP}=14$ & DAST; DEQ; MINI & Cue-dependent Go/No go & $\begin{array}{l}\text { Improved inhibition } \\
\text { after administration of } \\
\text { cocaine }\end{array}$ \\
\hline Fillmore et al. ${ }^{24}$ & $\mathrm{GP}=12$ & DAST; DEQ; MINI & $\begin{array}{l}\text { Cue-dependent Go/No- } \\
\text { Go; Stop signal }\end{array}$ & $\begin{array}{l}\text { Improved inhibition } \\
\text { after administration of } \\
\text { cocaine }\end{array}$ \\
\hline $\begin{array}{l}\text { Fernández-Serrano } \\
\text { et al. }{ }^{29}\end{array}$ & $\begin{array}{l}\mathrm{CG}=30 \\
\mathrm{GP}=60\end{array}$ & $\begin{array}{l}\text { FAS; RFFT; IGT; IRAB; OTM; R-SAT; } \\
\text { Digits, Cubes, Similarities, and } \\
\text { Categorization (WAIS-III) }\end{array}$ & $\begin{array}{l}\text { 5DT; } \\
\text { Color-Word Stroop }\end{array}$ & Yes (GP) \\
\hline $\begin{array}{l}\text { Fernández-Serrano } \\
\text { et al. }{ }^{30}\end{array}$ & $\begin{array}{l}\mathrm{CG}=65 \\
\mathrm{GCO}=46\end{array}$ & $\begin{array}{l}\text { IRAB; Probabilistic reversal learning task; } \\
\text { R-SAT; UPPS-P }\end{array}$ & $\begin{array}{l}\text { Color-Word Stroop; } \\
\text { Go/No go }\end{array}$ & Yes (GCO) \\
\hline Hester et al. ${ }^{31}$ & $\begin{array}{l}\mathrm{CG}=22 \\
\mathrm{GCO}=21\end{array}$ & SCID-I & $\begin{array}{l}\text { BAT; EAT; } \\
\text { Go/No-Go }\end{array}$ & Yes (GCO) \\
\hline Sellaro et al. ${ }^{32}$ & $\begin{array}{l}\mathrm{CG}=17 \\
\mathrm{GP}=17\end{array}$ & MINI; MPR & Simon Task & Yes (GP) \\
\hline Kjome et al. ${ }^{33}$ & $\begin{array}{l}\mathrm{CG}=20 \\
\mathrm{GCO}=66\end{array}$ & ASI; BIS-11; IGT; SCID & IMT & Yes (GCO) \\
\hline Li et al. ${ }^{34}$ & $\begin{array}{l}\mathrm{CG}=41 \\
\mathrm{GCO}=18\end{array}$ & SCID & Stop-Signal & Yes (GCO) \\
\hline Liu et al. ${ }^{35}$ & $\begin{array}{l}\mathrm{CG}=50 \\
\mathrm{GCO}=123\end{array}$ & SCID & Cocaine Stroop & Yes (GCO) \\
\hline Madoz-Gurpide et al. ${ }^{36}$ & $\begin{array}{l}\mathrm{CG}=27 \\
\mathrm{GCO}=24\end{array}$ & $\begin{array}{l}\text { BADS; EHI; MINI; Digits (WAIS-III); } \\
\text { TMT; WCST }\end{array}$ & Rule Shift Cards (BADS) & Yes (GCO) \\
\hline Pike et al. ${ }^{37}$ & $\begin{aligned} \text { GCOCGo } & =45 \\
\text { GCONGo } & =45\end{aligned}$ & Not stated. & ABBA (cued Go/No-Go) & Yes (GCOCGo) \\
\hline Ruiz et al. ${ }^{38}$ & $\begin{array}{l}\text { Experiment } 1 \text { : } \\
\mathrm{CG}=20 \\
\mathrm{GRCOU}=20 \\
\text { Experiment } 2: \\
\mathrm{CG}=16 \\
\mathrm{GCCOU}=16\end{array}$ & $\begin{array}{l}\text { Boston Naming Test; MPR; } \\
\text { MINI; MST; SCID; Verbal Fluency Test }\end{array}$ & Semantic blocking task & $\begin{array}{l}\text { Yes (GRCOU and } \\
\text { GCCOU) }\end{array}$ \\
\hline Soar et al. ${ }^{39}$ & $\begin{array}{l}\mathrm{CG}=18 \\
\mathrm{GP}=17 \\
\mathrm{GRCOU}=21\end{array}$ & BSI; NART-R; SPQ-B & Latent inhibition task & Yes (GRCOU) \\
\hline van der Plas et al. ${ }^{40}$ & $\begin{array}{l}\mathrm{CG}=36 \\
\mathrm{GCO}=27 \\
\mathrm{GA}=33 \\
\mathrm{GMET}=38\end{array}$ & IGT; SCID; Tic Tac Toe; WCST & $\begin{array}{l}\text { Cued Go/No-Go; } \\
\text { Stop-signal }\end{array}$ & $\begin{array}{l}\text { No } \\
\text { Differences in } \\
\text { executive functioning, } \\
\text { by sex and by type of } \\
\text { drug, were observed }\end{array}$ \\
\hline Verdejo-Garcia et al. ${ }^{41}$ & $\mathrm{GP}=38$ & $\begin{array}{l}\text { Changes: Test of Cognitive Flexibility; } \\
\text { IRAB; LNS, Arithmetic, Similarities and } \\
\text { Digits (WAIS-III) }\end{array}$ & Color-Word Stroop & Yes (GP) \\
\hline $\begin{array}{l}\text { Verdejo-Garcia \& } \\
\text { Perez-Garcia }{ }^{20}\end{array}$ & $\begin{array}{l}\mathrm{CG}=37 \\
\mathrm{GCO}=45 \\
\mathrm{GH}=28\end{array}$ & $\begin{array}{l}\text { Category test; CBT; FAS; IGT; LNS, } \\
\text { Arithmetic, Digits, and Similarities } \\
\text { (WAIS-III); RFFT; Spatial span (WMS- } \\
\text { III); WAT; WCST }\end{array}$ & $\begin{array}{l}\text { 5DT; } \\
\text { Color-Word Stroop; } \\
\text { Go/No-Go }\end{array}$ & Yes (GCO) \\
\hline Verdejo-Garcia et al. ${ }^{42}$ & $\begin{array}{l}\mathrm{CG}=30 \\
\mathrm{GCO}=39 \\
\mathrm{GH}=25\end{array}$ & IGT; IRAB; WAT & $\begin{array}{l}\text { 5DT; } \\
\text { Color-Word Stroop; } \\
\text { Go/No-Go }\end{array}$ & Yes (GCO and $\mathrm{GH})$ \\
\hline
\end{tabular}




\begin{tabular}{lllll}
\hline Authors & Sample & Clinical and cognitive assessments & Inhibition assessment & $\begin{array}{l}\text { Impaired } \\
\text { inhibition? }\end{array}$ \\
\hline Vonmoos et al. ${ }^{43}$ & $\mathrm{CG}=68$ & ADHD-SR; BDI; CCQ; MWT-B; SCID-I & BIS-11; & No \\
& GCCOU $=30$ & & $\begin{array}{l}\text { RVIPT; } \\
\text { Stop-Signal; TCINS }\end{array}$ \\
Winhusen et al. ${ }^{44}$ & GRCOU $=68$ & & $\begin{array}{l}\text { Bis-11; Color-Word Stroop Yes (GCO) } \\
\text { (Comalli-Kaplan version) }\end{array}$ \\
\hline
\end{tabular}

ABBA = Attentional Bias-Behavioural Activation Task; ADHD-SR = Attention Deficit Hyperactivity Disorder Self-rating Scale; ASI = Addiction Severity Index; BADS = Behavioural Assessment of the Dysexecutive Syndrome; BAT = Behavioural Adaptation Task; BDI = Beck Depression Inventory; BIS-11 = Barratt Impulsiveness Scale version 11; BPRS = Brief Psychiatric Rating Scale; BSI = The Brief Symptom Inventory; CBT = Cognitive bias task; CCQ: Cocaine Craving Questionnaire; CWIT $=$ Delis-Kaplan Executive Function System Color-Word Interference Test; DAST $=$ Drug Abuse Screening Test; D2 = Concentrated Attention Test; DEQ = Drug Effect Questionnaire; EAT = Error Awareness Task; EHI = Edinburgh Handedness Inventory; FAS = Verbal fluency test; 5DT = 5-Digit Test; GA = group of alcohol users; $\mathrm{CG}=$ control group; GCO = group of cocaine users; GCOCGo = group of cocaine users shown cocaine-related Go stimuli; GCONGo = group of cocaine users shown neutral Go stimuli; GCDCB = group of patients with cocaine dependency and Cluster B disorder comorbidity; GCDCC = group of patients with cocaine dependency and Cluster C disorder comorbidity; GH = group of heroin users; GMET = group of methamphetamine users; GP = group of polysubstance users; GCCOU = group of chronic cocaine users; GRCOU = group of recreational cocaine users; IGT = Iowa gambling task; IMT = Immediate Memory Task; IOR = Inhibition of Return Task; IRAB = Interview for Research on Addictive Behaviour; PG = pathological gamblers; K-BIT = Kaufman Brief Intelligence Test; LNS = Letter Number Sequencing; MINI = Mini International Neuropsychiatric Interview; MPR = Raven Progressive Matrices; MST = Memory Span Test; MWT-B = The Mehrfach-wahl Wortschatz Intelligenz test; NART-R = National Adult Reading Test; N-Back = N-Back Test; OTM = Oral Trail Making; PBQ = Personality Belief Questionnaire; PHQ = The Patient Health Questionnaire; RFFT = Ruff figural fluency test; R-SAT = Revised Strategy Application Test; RVIPT = Rapid Visual Information Processing Task; SCID and SCID-I = Structured Clinical Interview for DSM-IV; SPO-B = The Brief Schizotypal Personality Questionnaire; WAT = Word Accenting Test; TCINS = Temperament and Character Inventory Novelty Seeking Scale; TMT = Trail Making Test; UPPS-P = Impulsive Behavior Scale; WAIS-III = Wechsler Adult Intelligence Scale III; WCST = Wisconsin Card Sorting Test; WMS-III = Wechsler Memory Scale III; WURS = Wender Utah Rating Scale.

Table 2 - Results of inhibitory control assessments in studies investigating inhibition and its neural correlates in samples of cocaine/crack users

\begin{tabular}{|c|c|c|c|c|c|}
\hline Study & Sample & Clinical/cognitive measures & $\begin{array}{l}\text { Imaging } \\
\text { studies }\end{array}$ & $\begin{array}{l}\text { Measures of inhibitory } \\
\text { control }\end{array}$ & $\begin{array}{l}\text { Inhibitory } \\
\text { control deficits? }\end{array}$ \\
\hline $\begin{array}{l}\text { Albein-Urios et } \\
\text { al. } 45\end{array}$ & $\begin{array}{l}\mathrm{CG}=34 \\
\mathrm{GCO}=44 \\
\mathrm{GCOCB}=32\end{array}$ & $\begin{array}{l}\text { Cancellation Test; Category Test; } \\
\text { D2; LNS (WAIS-III); N-back; PBQ; } \\
\text { UPPS-P }\end{array}$ & fMRI & Color-Word Stroop & $\begin{array}{l}\text { Yes (GCO and } \\
\text { GCOCB) }\end{array}$ \\
\hline $\begin{array}{l}\text { Barros-Loscertales } \\
\text { et al. }{ }^{46}\end{array}$ & $\begin{array}{l}\mathrm{CG}=16 \\
\mathrm{GCO}=16\end{array}$ & $\begin{array}{l}\text { Color-Word Stroop; Matrix } \\
\text { Reasoning test (WAIS-III) }\end{array}$ & fMRI & Counting Stroop & Yes (GCO) \\
\hline Bell et al. ${ }^{47}$ & $\begin{array}{l}\mathrm{CG}=45 \\
\mathrm{GACO}=27\end{array}$ & SCID & fMRI & Go/No-Go & No \\
\hline Bell et al. ${ }^{48}$ & $\begin{array}{l}\mathrm{CG}=19 \\
\mathrm{GACO}=20\end{array}$ & BIS- $11 ;$ CCQ & fMRI & $\begin{array}{l}\text { Cocaine cue task; } \\
\text { Go/No-Go }\end{array}$ & No \\
\hline $\begin{array}{l}\text { Castelluccio et } \\
\text { al. } 49\end{array}$ & $\begin{array}{l}\mathrm{CG}=35 \\
\mathrm{GCO}=30 \\
\mathrm{GECO}=29\end{array}$ & $\begin{array}{l}\text { BART; BIS-11; BIS/BAS; EDT; } \\
\text { Padua Inventory; SPSRQ; SSS } \\
\text { Form V }\end{array}$ & fMRI & Go/No-Go & No \\
\hline Connolly et al. ${ }^{50}$ & $\begin{array}{l}\mathrm{CG}=9 \\
\mathrm{GCOST}=9 \\
\mathrm{GCOLT}=9\end{array}$ & BIS-11; BPAQ; KMSK & fMRI & Go/No-Go & No \\
\hline Elton et al. ${ }^{51}$ & $\begin{array}{l}\mathrm{CG}=27 \\
\mathrm{GCO}=38\end{array}$ & BDI; SCID-I & fMRI & $\begin{array}{l}\text { BIS-11; } \\
\text { Stop-signal }\end{array}$ & No \\
\hline Hester et al. ${ }^{52}$ & $\begin{array}{l}\mathrm{GACO}=15 \\
\mathrm{CG}=15\end{array}$ & SCID-I; WRAT & fMRI & $\begin{array}{l}\text { Go/No-Go with monetary } \\
\text { punishment }\end{array}$ & Yes (GACO) \\
\hline Morie et al. ${ }^{53}$ & $\begin{array}{l}\mathrm{CG}=27 \\
\mathrm{GCO}=23\end{array}$ & BIS-11; BPAQ; KMSK; LHA; SCID & EEG & Go/No-Go & Yes (GCO) \\
\hline Morie et al. ${ }^{54}$ & $\begin{array}{l}\mathrm{CG}=21 \\
\mathrm{GAP}=21\end{array}$ & ASI; CPCSS; CSSA; SCID; SHPS & EEG & $\begin{array}{l}\text { Go/No-Go; } \\
\text { Go/No-Go with emotional bias }\end{array}$ & No \\
\hline $\begin{array}{l}\text { Morein-Zamir et } \\
\text { al. }{ }^{55}\end{array}$ & $\begin{array}{l}\mathrm{CG}=41 \\
\mathrm{GHSD}=32 \\
\mathrm{GHSD}=39\end{array}$ & $\begin{array}{l}\text { AUDIT; DAST-20; NART; OCDUS; } \\
\text { SCID }\end{array}$ & fMRI & Stop-signal & Yes (GHSD) \\
\hline Smith et al. ${ }^{56}$ & $\begin{array}{l}\mathrm{CG}=47 \\
\mathrm{GHSD}=42 \\
\mathrm{GHSD}=49\end{array}$ & $\begin{array}{l}\text { AUDIT; BDI-II; DAST-20; OCDUS; } \\
\text { SCID }\end{array}$ & fMRI & Color-Word Stroop & Yes (GHSD) \\
\hline
\end{tabular}

ASI = Addiction Severity Index; AUDIT = Alcohol Use Disorder Identification Test; BART = Balloon Analog Risk Task; BDI and BDI-II = Beck Depression Inventory; BIS-11 = Barratt Impulsiveness Scale version 11; BIS/BAS = Behavioral Inhibition/Activation System; BPAQ = Buss-Perry Aggression Questionnaire; CCQ: Cocaine Craving Questionnaire; CPCSS = Chapman Physical and Chapman Social Scales; CSSA = Cocaine Selective Severity Assessment Scale; DAST-20 = Drug Abuse Screening Test; D2 = Concentrated Attention Test; EDT = Experiential Discounting Task; EEG = electroencephalography; fMRI = Functional magnetic resonance imaging; $C G$ = control group; GCO = group of cocaine users; GCOST = group of cocaine users abstinent over short term; GCOLT = group of cocaine users abstinent over long term; GACO = group of abstinent cocaine users; GCOCB = group of patients with cocaine dependency and Cluster B disorder comorbidity; GHSD = group of patients with stimulant drug dependency; GECO = group of ex-cocaine users; GHSD = group of healthy siblings of patients with dependency; GAP = group of abstinent polysubstance users; KMSK = Kreek-McHugh-Schluger-Kellog Scale; LHA = Life History of Aggression; LNS = Letter Number Sequencing; NART = National Adult Reading Test; N-Back = N-Back Test; OCDUS = Obsessive Compulsive Drug Use Scale; PBQ = Personality Belief Questionnaire; SCID and SCID-I = Structured Clinical Interview for DSM-IV; SHPS = Snaith Hamilton Pleasure Scale; SPSRQ = Sensitivity to Punishment and Sensitivity to Reward Questionnaire; SSS Form V = Sensation Seeking Scale; UPPS-P = Impulsive Behavior Scale; WAIS-III = Wechsler Adult Intelligence Scale III; WRAT = Wide Range Achievement Test. 
in terms of reaction times (RT) and correctness of responses when faced with rule changes, measured by quantitative and qualitative analysis of errors made by the person being tested. Errors of omission are errors in identification of the stimulus, which occurr when the examinee does not produce a response. Errors of comission are perseverative errors or "false alarms", which occurr when the examinee produces an incorrect response. Table 3 lists the instruments used in the articles reviewed and the frequency of use.

\section{Discussion}

The analysis of studies included in this review showed that when compared to controls with no history of PS abuse, cocaine and/or crack users (CU) exhibited high levels of impulsiveness, ${ }^{30,33,43,47-49}$ and also inhibition deficits (errors of omission and commission). $28,30,31,33,36,42,53$ Differences were also observed in processing velocity, with $\mathrm{CU}$ exhibiting a greater variability in RT than controls. ${ }^{34-36,46}$ The studies analyzed verified levels of impulsiveness using measures (scales and self-report questionnaires) that include questions related to control of impulses in everyday situations. Inhibitory control was evaluated using tests and tasks designed to assess patterns of response to a range of different stimuli.

Failures of performance monitoring were observed in the samples of $\mathrm{CU}$ during execution of the inhibition tasks. ${ }^{31,34,53}$ These failures were detected by an absence of increase in RT after an error (post-error slowing), which is expected to occur when a person is capable of realizing that they have made an error. Difficulties with monitoring were also detected among $\mathrm{CU}$, manifest in an inability to increase cognitive control when faced with negative consequences, during execution of a Go/No-Go task with monetary punishment. ${ }^{52}$ It can be concluded that these findings are associated with impaired cognitive control, which appears to be related to mechanisms of craving, in which a person resumes use of PS without considering the negative consequences of this use for multiple aspects of life.

It is of interest that when $\mathrm{CU}$ were compared to controls they exhibited similar acquisition of learning, but impaired learning of discriminatory reversibility, with inappropriate responses to rule changes. ${ }^{28}$ It therefore appears that cocaine and/or crack consumption has an impact on abilities that specifically involve inhibitory control. Furthermore, when an impulsive personality and cocaine and/or crack use are present in combination, they appear to be associated with greater impairments involving inhibition and compulsion. ${ }^{30}$

It also appears, acording to the studies reviewed, that different patterns of cocaine and/or crack use have an influence on inhibitory control. Recreational cocaine and/or crack users (RCU) exhibited inhibition deficits, observed as greater difficulty with producing responses to conflicting stimuli and a reduced capacity to filter out irrelevant stimuli, when compared to controls. ${ }^{17,27,39}$

Table 3 - Instruments used to assess inhibitory control

\begin{tabular}{lc}
\hline Instrument & Frequency \\
\hline Attentional-Bias-Behavioral Activation Task (ABBA) & 1 \\
Behavioural Adaptation Task (BAT) & 1 \\
Cocaine Cue Task & 1 \\
Cocaine Stroop & 1 \\
Color-Word Interference Test (CWIT) & 2 \\
Color-Word Stroop & 9 \\
Counting Stroop & 1 \\
Cue-dependent Go/No-Go & 5 \\
Error Awareness Task (EAT) & 1 \\
5-Digit Test & 3 \\
Go/No-Go & 10 \\
Go/No-Go with monetary punishment & 1 \\
Go/No-Go with emotional bias & 1 \\
Immediate Memory Task (IMT) & 1 \\
Inhibition of Return Task (IOR) & 1 \\
Latent Inhibition Task & 1 \\
Rule Shift Cards & 1 \\
Semantic Blocking Task & 1 \\
Simon Task & 1 \\
Stop-Signal & 6 \\
\hline
\end{tabular}


In a language production task, both RCU and chronic cocaine and/or crack users (CCU) exhibited increased vulnerability to semantic interference. ${ }^{38}$ Just one study did not report inhibition deficits in RCU and $\mathrm{CCU}$, but both groups did exhibit elevated levels of impulsiveness (assessed by questionnaire). ${ }^{43}$ The authors investigated motor impulsiveness and response inhibition using a visual processing task and a stop-signal task and attributed the absence of inhibition deficits in their samples to methodological issues, such as adoption of different measures and methods for assessment of inhibitory control (two behavioral tasks and selfreport questionnaires) and exclusion of participants with psychiatric and personality comorbidities, and to differences between samples (clinical and control). The majority of these results indicate that occasional and recreational cocaine and/or crack use can be associated with impairment of cognitive control functions, even in people who take small doses of the drug and do not have a history of chronic or frequent use.

In turn, chronic use of cocaine and/or crack appears to have a greater impact on cognitive functioning. Duration, quantity, and frequency of cocaine and/ or crack use were all associated with worse inhibition performance, indicating the possibility that cocaine and/or crack impact on inhibitory control, which was detected using a variety of measures. ${ }^{29,36,41}$ As such, chronic cocaine and/or crack use may be associated with executive dysfunctions and increased impairment of inhibition, which can have negative consequences for CU's functionality and prognosis; consequences which could culminate in abandonment of treatment.

The acute effects of cocaine on inhibitory control were investigated in two studies that administrated doses of the drug to their samples. ${ }^{23,24}$ In both studies, CU were divided into four groups according to the dose of cocaine administered $(0,100 \mathrm{mg}, 200$ $\mathrm{mg}$, or $300 \mathrm{mg}$ ), before responding to measures of inhibition. Improved inhibition performance was observed in terms of reduced RT in a stop-signal task, after administration of doses of $100 \mathrm{mg}$ and $200 \mathrm{mg}$ of cocaine. No effects on velocity of response emission were observed after administration of cocaine when the dose was $300 \mathrm{mg}$. Notwithstanding the ethical issues involved in studies with this type of design, these findings highlight the importance of collecting information on patterns of cocaine and/or crack consumption, and of controlling consumption of these substances when assessing $\mathrm{CU}$ (using laboratory tests, for example). These measures appear to be necessary since different cocaine dosages can have different effects on the performance of those examined and can even mask real cognitive dysfunctions.
With regard to cognitive rehabilitation, five studies reported evidence of recovery of inhibitory control functions after cessation of cocaine and/or crack use. ${ }^{47-49,50,54}$ With abstinence durations varying from 2 weeks to 2 years, samples of abstinent users exhibited preserved performance in inhibition tasks, but high levels of impulsiveness were described in the samples of three of these studies. ${ }^{47-49}$ It should be pointed out that impulsiveness was investigated using scales and questionnaires involving questions on participants' everyday lives, in other words, using more ecological measures than those used to assess inhibitory control. This factor may be linked to the higher frequency of positive results for impulsiveness in the studies analyzed, compared with findings of inhibitory control deficits. Additionally, these results could indicate an increased predisposition to problematic drug use among more impulsive people.

Psychiatric and personality disorder comorbidities constitute relevant information when evaluating CU. Studies that included these variables in their designs found higher levels of anhedonia among CU, compared to healthy controls ${ }^{53}$ and worse inhibitory control performance in $\mathrm{CU}$ with cluster $\mathrm{B}$ personality comorbidities (histrionic, borderline, anti-social, and narcissistic disorders), when compared with $\mathrm{CU}$ without comorbid personality disorders and with healthy controls. ${ }^{26,45} \mathrm{Crack} /$ cocaine users also exhibited similar inhibition deficits to people with diagnoses of pathological gambling, but exhibited higher levels of impulsiveness. ${ }^{25}$ These findings demonstrate the importance of including measures of comorbidities in cognitive and behavioral assessments of $\mathrm{CU}$, since they can be associated with worse performance in the tasks employed. For example, in a study by Li et al. ${ }^{34}$ there were participants with posttraumatic stress disorder in the sample of $\mathrm{CU}$, but the possible impact of this comorbidity on participants' performance was not taken into consideration, limiting the possibilities for generalization of the study's findings. Nevertheless, it should be acknowledged that assessments are subject to logistical limitations, such as time constraints and the extent of the test battery. Researchers therefore very often have to choose between including one or another instrument. Notwithstanding, it is still recommended that measures for screening comorbidities be included whenever possible.

Genetic and family factors can be related to SRD, since they are complex and multifactorial phenomena. Two studies compared the performance of CU with nonuser siblings, with the objective of identifying patterns of cognitive performance that could be associated with greater vulnerability to PS use. In one study, both users of stimulant PS (cocaine and/or crack and 
amphetamines) and their siblings who were not users exhibited impairments of inhibition and of processing velocity, when compared to controls, ${ }^{56}$ but in another study with a similar design only the group of users exhibited impaired inhibition. ${ }^{55}$ On the basis of these results, no patterns of cognitive performance were identified in the comparison between users and nonuser siblings. Nevertheless, studies with this type of design could contribute to improving understanding of the factors associated with SRD and it is relevant to conduct further studies with this objective.

Attentional bias for PS use has also been investigated because it is possible that people with SRD may exhibit cognitive bias towards pathways associated with their drug of choice. They would thus tend to direct their attention towards stimuli related to the drug, in detriment to other stimuli. ${ }^{57,58}$ Attentional bias would therefore be an individual readiness to process certain stimuli more than others, due to the appetitive value attributed to them. ${ }^{59}$ Thus, research using tasks with stimuli related to cocaine and/or crack attempt to better understand this process, but there is no consensus among the articles reviewed here. In two studies, use of tasks with this type of stimuli was associated with worse inhibition performance in $\mathrm{CU}$, detected as a greater variability in $\mathrm{RT}^{35}$ and increased inhibition deficits in responses. ${ }^{37}$ In contrast, another study using a similar task did not detect this association. ${ }^{48}$ It is therefore important to understand the possible dysfunctions related to information processing exhibited by $\mathrm{CU}$, such as attentional bias for cocaine and/or crack, for example, since such findings could contribute to treatment, to prevention of relapses, and to cognitive rehabilitation of these people.

A very small proportion of the studies reviewed reported negative results for inhibition impairments in $\mathrm{CU} .40,43,51$ One of these studies compared inhibition performance in samples of users of different PS (alcohol, cocaine and/or crack, methamphetamine and controls) and did not detect differences between the groups in terms of inhibition performance. ${ }^{40}$ However, the $\mathrm{CU}$ group exhibited impairments in all of the other cognitive functions assessed (decision making, working, and cognitive flexibility). It is also important to point out that only one measure of inhibition was used and that when variables such as age and educational level of participants were controlled, differences previously detected lost their significance. It is known that issues related to non-uniformity of samples (age, educational level, IQ) constitute a major challenge to researchers in this field, because it is common for people with SRD to be older and have lower educational levels than control samples. This appears to be one of the factors that contributed to the discrepant findings in this study.
Another study that reported an absence of inhibition deficits in $\mathrm{CU}$ was conducted by Vonmoos et al., ${ }^{43}$ although in this study CU did exhibit elevated impulsiveness. As discussed previously, the authors identified several factors that could have contributed to these negative findings with relation to inhibition deficits. One of these factors is related to assessment of a "relatively pure" sample of $\mathrm{CU}$, excluding multiple PS users and participants with psychiatric and personality comorbidities, in contrast with the majority of studies in the field. This methodological choice results in exclusion of people who are more representative of "real life", since the profile most often described is of CU with a history of multiple PS use who have adopted cocaine and/or crack as their drug of choice, and presence of comorbidities is also very frequent.

A similar result was reported by Elton et al., ${ }^{51}$ who also failed to detect inhibition deficits in $\mathrm{CU}$ in comparison with controls. Once more, the CU did exhibit elevated impulsiveness. Although the $\mathrm{CU}$ exhibited performance equivalent to the controls in the inhibition task, functional magnetic resonance imaging (fMRI) linked cocaine and/or crack consumption to changes in multiple neural networks that manage inhibitory control processes, including response execution, response inhibition, error processing, and response monitoring. These abnormalities of cerebral activation could indicate that compensatory mechanisms have been activated to deal with deficits in underlying inhibitory capabilities.

Changes to the neural circuits involved in management of cognitive and behavioral processes in PS users have been described in the literature. ${ }^{11-13}$ Despite this, no consensus on the cerebral abnormalities present in $\mathrm{CU}$ was identified in the analysis of research investigating the neural correlates of inhibitory control. Some studies reported hypoactivation of the ventrolateral prefrontal cortex, the anterior cingulate, $52,55,56,60$ the right inferior frontal gyrus, the right parietal inferior gyrus, and the right superior temporal gyrus, ${ }^{46}$ whereas another study observed hyperactivation of these same regions. ${ }^{50}$ Additionally, reduced activation of the dorsal anterior cingulate cortex was associated with relapse in men and women, together with reduced activation of the thalamus in women and of the left insula in men. ${ }^{61}$ It was not therefore possible to identify patterns of cerebral hypoactivation and hyperactivation that could reveal a profile of neurocognitive functioning or dysfunctions in $\mathrm{CU}$. Factors associated with individual differences and the different patterns of consumption of cocaine and/or crack could be related to the inconsistencies in these studies.

This review is subject to certain limitations. Searching on three databases and inclusion of articles written in Portuguese, English, and Spanish does 
not capture all publications on the subject under review. However, the search terms chosen were very comprehensive, with the aim of including the highest possible number of articles. Additionally, English has been adopted as the reference when conducting literature reviews. Another limitation is the period covered in the review (ten years). It was decided to limit the period reviewed because older reviews are already available. Additionally, the objective of this review was to compile the most recent findings on evaluation of inhibitory control in $\mathrm{CU}$, in order to chart developments in new measures and techniques for cognitive assessment with this focus. It should also be pointed out that many different studies were found that differed in terms of method, objective, and results, which underscores the need for literature reviews to compile data that is relevant to planning more appropriate treatments that are better adapted to the specifics of this population.

\section{Conclusions}

This review was able to conclude that $90 \%$ of the articles analyzed provide evidence of cognitive impairments involving inhibitory control in cocaine and/ or crack users. They exhibited difficulties with cognitive processing, manifest in failures of emission, inhibition, and monitoring of responses, during execution of tasks that are designed to evaluate inhibition. Elevated levels of impulsiveness were also reported, even by studies that observed negative results for inhibition deficits. These findings may be related to the measures used to evaluate impulsiveness (scales and questionnaires involving everyday situations) and suggest that high levels of impulsiveness (pre-morbid) may be a factor of vulnerability to abuse of PS and relapse, confirming the specialized literature that states that impaired inhibitory control and elevated impulsiveness are central deficits in substance abuse. ${ }^{18,22}$

In general, the studies reviewed did not contain clear information on the route of cocaine administration (whether inhaled, injected, or smoked - crack). It should be borne in mind that although crack is a drug that is derived from cocaine, it exhibits distinct patterns of consumption, route of administration, and potential for addiction, which can cause more severe cognitive and behavioral impairments than those exhibited by users of inhaled cocaine. In this respect, there is a lack of studies investigating the specific clinical, cognitive, and behavioral characteristics of users of crack, which is a drug whose consumption is increasing notably.

\section{Disclosure}

No conflicts of interest declared concerning the publication of this article.

\section{References}

1. Faller $S$, Peuker $A C$, Sordi $A$, Stolf $A$, Souza-Formigoni $M L$, Cruz MS, et al. Who seeks public treatment for substance abuse in Brazil? Results of a multicenter study involving four Brazilian state capitals. Trends Psychiatry Psychother. 2014;36:193-202.

2. Haas C, Karila L, Lowenstein W. [Cocaine and crack addiction: a growing public health problem]. Bull Acad Natl Med. 2009;193:947-62; discussion 962-3.

3. Diehl A, Cordeiro DC, Laranjeira R. Dependência química: prevenção, tratamento e políticas públicas. Porto Alegre: Artmed; 2011.

4. Friedman AS, Glassman K, Terras BA. Violent behavior as related to use of marijuana and other drugs. J Addict Dis. 2001;20:4972.

5. Ribeiro M, Dunn J, Sesso R, Dias AC, Laranjeira R. Causes of death among crack cocaine users. Rev Bras Psiquiatr. 2006;28:196202.

6. Riezzo I, Fiore C, De Carlo D, Pascale N, Neri M, Turillazzi E, et al. Side effects of cocaine abuse: multiorgan toxicity and pathological consequences. Curr Med Chem. 2012;19:5624-46.

7. Carlini EA, Galduróz JCF, Noto AR, Fonseca AM, Carlini CM, Oliveira LG, et al. II Levantamento domiciliar sobre uso de drogas psicotrópicas no Brasil: estudo envolvendo as 108 maiores cidades do país - 2005. São Paulo: Centro Brasileiro de Informações sobre Drogas Psicotrópicas, Universidade Federal de São Paulo; 2007.

8. Galduróz JC, Noto AR, Carlini EA. IV Levantamento sobre o uso de drogas entre estudantes de $1^{\circ}$ e $2^{\circ}$ graus em 10 capitais brasileiras. São Paulo: Centro Brasileiro de Informações sobre Drogas Psicotrópicas (CEBRID). 1997.

9. da Cunha SM, Araujo, RB, Bizarro L. Profile and pattern of crack consumption among impatients in a Brazilian psychiatric hospital. Trends Psychiatry Psychother. 2015;37:126-32.

10. Pedrero-Perez EJ, Rojo-Mota G, Ruiz-Sanchez de Leon JM, Llanero-Luque M, Puerta-Garcia C. [Cognitive remediation in addictions treatment]. Rev Neurol. 2011;52:163-72.

11. Suska A, Lee BR, Huang YH, Dong Y, Schluter OM. Selective presynaptic enhancement of the prefrontal cortex to nucleus accumbens pathway by cocaine. Proc Natl Acad Sci U S A. 2013;110:713-8.

12. Volkow ND, Fowler JS. Addiction, a disease of compulsion and drive: involvement of the orbitofrontal cortex. Cereb Cortex. 2000;10:318-25.

13. Volkow ND, Fowler JS, Wang GJ. The addicted human brain: insights from imaging studies. J Clin Invest. 2003;111:1444-51.

14. Patton JH, Stanford MS, Barratt ES. Factor structure of the Barratt impulsiveness scale. J Clin Psychol. 1995;51:768-74.

15. Pedrero-Perez EJ, Ruiz Sánchez de León JM. [Subtypes of cocaine addicts with and without associated problematic alcohol use: towards a neuropsychology of personality applied to clinical practice]. Adicciones. 2012;24:291-300.

16. Moeller FG, Barratt ES, Dougherty DM, Schmitz JM, Swann AC. Psychiatric aspects of impulsivity. Am J Psychiatry. 2001;158:1783-93.

17. Colzato LS, Hommel B. Recreational use of cocaine eliminates inhibition of return. Neuropsychology. 2009;23:125-9.

18. Koob GF, Volkow ND. Neurocircuitry of addiction. Neuropsychopharmacology. 2010;35:217-38.

19. Almeida RMMd, Hammer C, Macuglia GR, Klein LA, Trentini LB, Tesmmer M. Uso de álcool, drogas, níveis de impulsividade e agressividade em adolescentes do Rio Grande do Sul. Psico (Porto Alegre). 2014;45:65-72.

20. Verdejo-Garcia A, Perez-Garcia M. Profile of executive deficits in cocaine and heroin polysubstance users: common and differential effects on separate executive components. Psychopharmacology (Berl). 2007;190:517-30.

21. Camí J, Farré M. Drug addiction. N Engl J Med. 2003;349:975-86. 
22. American Psychiatric Association. Diagnostic and Statistical Manual of Mental Disorders, Fifth Edition (DSM-5). Arlington: American Psychiatric Publishing; 2013.

23. Fillmore MT, Rush CR, Hays L. Cocaine improves inhibitory control in a human model of response conflict. Exp Clin Psychopharmacol. 2005; 13:327-35.

24. Fillmore MT, Rush CR, Hays L. Acute effects of cocaine in two models of inhibitory control: implications of non-linear dose effects. Addiction. 2006;101:1323-32.

25. Albein-Urios N, Martinez-Gonzalez JM, Lozano O, Clark L, VerdejoGarcia A. Comparison of impulsivity and working memory in cocaine addiction and pathological gambling: implications for cocaine-induced neurotoxicity. Drug Alcohol Depend. 2012;126:16.

26. Albein-Urios N, Martinez-Gonzalez JM, Lozano-Rojas O, VerdejoGarcia A. Executive functions in cocaine-dependent patients with Cluster B and Cluster C personality disorders. Neuropsychology. 2014;28:84-90.

27. Colzato LS, van den Wildenberg WP, Hommel B. Impaired inhibitory control in recreational cocaine users. Plos One. 2007;2:e1143.

28. Fillmore MT, Rush CR. Polydrug abusers display impaired discrimination-reversal learning in a model of behavioural control. J Psychopharmacol. 2006;20;24-32.

29. Fernández-Serrano MJ, Pérez-García M, Schmidt Río-Valle J, Verdejo-García A. Neuropsychological consequences of alcohol and drug abuse on different components of executive functions. J Psychopharmacol. 2010;24:1317-32.

30. Fernández-Serrano MJ, Perales JC, Moreno-López L, PérezGarcía M, Verdejo-García A. Neuropsychological profiling of impulsivity and compulsivity in cocaine dependent individuals. Psychopharmacology (Berl). 2012;219:673-83.

31. Hester R, Simões-Franklin C, Garavan H. Post-error behavior in active cocaine users: poor awareness of errors in the presence of intact performance adjustments. Neuropsychopharmacology. 2007;32:1974-84.

32. Sellaro R, Hommel B, Colzato LS. Increased response conflict in recreational cocaine polydrug users. Exp Brain Res. 2014;232:1139.

33. Kjome KL, Lane SD, Schmitz JM, Green C, Ma L, Prasla I, et al. Relationship between impulsivity and decision making in cocaine dependence. Psychiatry Res. 2010;178:299-304.

34. Li CS, Milivojevic V, Kemp K, Hong K, Sinha R. Performance monitoring and stop signal inhibition in abstinent patients with cocaine dependence. Drug Alcohol Depend. 2006;85:205-12.

35. Liu S, Lane SD, Schmitz JM, Green CE, Cunningham KA, Moeller FG. Increased intra-individual reaction time variability in cocainedependent subjects: role of cocaine-related cues. Addict Behav. 2012;37:193-7.

36. Madoz-Gurpide A, Blasco-Fontecilla H, Baca-Garcia E, OchoaMangado $\mathrm{E}$. Executive dysfunction in chronic cocaine users: an exploratory study. Drug Alcohol Depend. 2011;117:55-8.

37. Pike E, Marks KR, Stoops WW, Rush CR. Cocaine-related stimuli impair inhibitory control in cocaine users following short stimulus onset asynchronies. Addiction. 2015;110:1281-6.

38. Ruiz MJ, Paolieri D, Colzato LS, Bajo MT. Chronic and recreational use of cocaine is associated with a vulnerability to semantic interference. Psychopharmacology (Berl). 2015;232:1717-26.

39. Soar K, Dawkins L, Page F, Wooldridge J. Recreational cocaine use is associated with attenuated latent inhibition. Addict Behav. 2015;50:34-9.

40. van der PlasEA, Crone EA, van den Wildenberg WP, Tranel D, Bechara A. Executive control deficits in substance-dependent individuals: a comparison of alcohol, cocaine, and methamphetamine and of men and women. J Clin Exp Neuropsychol. 2009;31:706-19.

41. Verdejo-Garcia AJ, Lopez-Torrecillas F, Aguilar de Arcos F, PerezGarcia M. Differential effects of MDMA, cocaine, and cannabis use severity on distinctive components of the executive functions in polysubstance users: a multiple regression analysis. Addict Behav. 2005;30:89-101.

42. Verdejo-Garcia AJ, Perales JC, Perez-Garcia M. Cognitive impulsivity in cocaine and heroin polysubstance abusers. Addict Behav. 2007;32:950-66.

43. Vonmoos M, Hulka LM, Preller KH, Jenni D, Schulz C, Baumgartner $M R$, et al. Differences in self-reported and behavioral measures of impulsivity in recreational and dependent cocaine users. Drug Alcohol Depend. 2013;133:61-70.
44. Winhusen T, Lewis D, Adinoff B, Brigham G, Kropp F, Donovan DM, et al. Impulsivity is associated with treatment non-completion in cocaine- and methamphetamine-dependent patients but differs in nature as a function of stimulant-dependence diagnosis. J Subst Abuse Treat. 2013;44:541-7.

45. Albein-Urios N, Martinez-Gonzalez JM, Lozano O, MorenoLopez L, Soriano-Mas C, Verdejo-Garcia A. Negative urgency, disinhibition and reduced temporal pole gray matter characterize the comorbidity of cocaine dependence and personality disorders. Drug Alcohol Depend. 2013;132:231-7.

46. Barros-Loscertales A, Bustamante JC, Ventura-Campos N, Llopis JJ, Parcet MA, Avila C. Lower activation in the right frontoparietal network during a counting Stroop task in a cocaine-dependent group. Psychiatry Res. 2011;194:111-8.

47. Bell RP, Foxe JJ, Ross LA, Garavan H. Intact inhibitory control processes in abstinent drug abusers (I): a functional neuroimaging study in former cocaine addicts. Neuropharmacology. 2014;82:143-50.

48. Bell RP, Garavan H, Foxe JJ. Neural correlates of craving and impulsivity in abstinent former cocaine users: towards biomarkers of relapse risk. Neuropharmacology. 2014;85:461-70.

49. Castelluccio BC, Meda SA, Muska CE, Stevens MC, Pearlson GD. Error processing in current and former cocaine users. Brain Imaging Behav. 2014;8:87-96.

50. Connolly CG, Foxe JJ, Nierenberg J, Shpaner M, Garavan H. The neurobiology of cognitive control in successful cocaine abstinence. Drug Alcohol Depend. 2012;121:45-53.

51. Elton A, Young J, Smitherman S, Gross RE, Mletzko T, Kilts CD. Neural network activation during a stop-signal task discriminates cocaine-dependent from non-drug-abusing men. Addict Biol. 2014;19:427-38.

52. Hester R, Bell RP, Foxe JJ, Garavan H. The influence of monetary punishment on cognitive control in abstinent cocaine-users. Drug Alcohol Depend. 2013;133:86-93.

53. Morie KP, De Sanctis P, Garavan H, Foxe JJ. Executive dysfunction and reward dysregulation: a high-density electrical mapping study in cocaine abusers. Neuropharmacology. 2014;85:397407.

54. Morie KP, Garavan H, Bell RP, De Sanctis P, Krakowski MI, Foxe JJ. Intact inhibitory control processes in abstinent drug abusers (II): a high-density electrical mapping study in former cocaine and heroin addicts. Neuropharmacology. 2014;82:151-60.

55. Morein-Zamir S, Simon Jones P, Bullmore ET, Robbins TW, Ersche KD. Prefrontal hypoactivity associated with impaired inhibition in stimulant-dependent individuals but evidence for hyperactivation in their unaffected siblings. Neuropsychopharmacology. 2013;38:1945-53.

56. Smith DG, Jones PS, Bullmore ET, Robbins TW, Ersche KD. Cognitive control dysfunction and abnormal frontal cortex activation in stimulant drug users and their biological siblings. Transl Psychiatry. 2013;3:e257.

57. Bradley BP, Mogg K, Wright T, Field M. Attentional bias in drug dependence: vigilance for cigarette-related cues in smokers. Psychol Addict Behav. 2003;17:66-72.

58. Peuker AC, Lopes FM, Bizarro L. Viés atencional no abuso de drogas: teoria e método. Psic Teor Pesq. 2009;25:603-9.

59. Williams JM, Mathews A, MacLeod C. The emotional Stroop task and psychopathology. Psychol Bull. 1996;120:3-24.

60. Liu S, Lane SD, Schmitz JM, Waters AJ, Cunningham KA, Moeller FG. Relationship between attentional bias to cocaine-related stimuli and impulsivity in cocaine-dependent subjects. Am J Drug Alcohol Abuse. 2011;37:117-22.

61. Luo X, Zhang S, Hu S, Bednarski SR, Erdman E, Farr OM, et al. Error processing and gender-shared and specific neural predictors of relapse in cocaine dependence. Brain. 2013;136:1231-44.

\section{Correspondence:}

\section{Fernanda Rasch Czermainski}

Instituto de Psicologia, Universidade Federal do Rio Grande do Sul

Rua Ramiro Barcelos, 2600, Bairro Santa Cecília

90035-003 - Porto Alegre, RS - Brazil

Tel.: +55 (51) 3308.5066 / +55 (51) 99835.3909

E-mail: ferrasch@gmail.com 